\title{
Diablotextion
}

\section{Perspectivas, toma de conciencia y consolidación de la historieta en el mundo académico}

\author{
LUZ C. SOUTO \\ JOSÉ MARTÍNEZ RUBIO \\ UNIVERSITAT DE VALĖNCIA
}

En la tradición hispánica la ubicación de la historieta en los estudios académicos había sido desatendida y relegada por aquello que los estudios críticos entendían por literatura, o entendían que merecía la pena interpretar, destacar y conservar como patrimonio en tanto que fenómeno literario. En primer lugar, por su carácter popular y por la asociación que, desde la alta cultura, se establecía entre su práctica y la recepción por parte de un público mayoritariamente infantil o juvenil. En segundo lugar, por el imaginario que este tipo de publicaciones infantiles o juveniles desarrollaban: héroes, aventuras, personajes estereotipados, lugares fantásticos, etc. En tercer lugar, por la estrecha relación que algunas de sus manifestaciones guardaban con disciplinas no literarias (tampoco lo eran para la crítica tradicional) como el periodismo, pues la viñeta servía de opinión, sátira, denuncia o ponderación de personajes o hechos de actualidad, o como la publicidad o el cartelismo.

Sin embargo, a partir de los años sesenta los rígidos canales de interpretación de la crítica literaria se ven desbordados por una serie de obras y, sobre todo, por una serie de estudios encaminados a dignificar las manifestaciones periféricas del arte y concederles cierto interés para el estudio de la literatura. En el caso que nos ocupa, cabe destacar el empeño de Umberto Eco en su clásico Apocalittici e integrati (1964) por estudiar desde la semiótica las imágenes de Superman y de Steve Canyon como promotores de determinados valores en la cultura de masas. No por casualidad, poco después Tom Wolfe teorizará y reivindicará en The New Journalism (1973) una serie 
de prácticas que venían realizándose en el periodismo norteamericano (y no solo) como combinación de periodismo y literatura en la que maestros como Norman Mailer, Truman Capote, el propio Wolfe o Rodolfo Walsh sentarían las bases de una estética interdisciplinar cuya senda llega hasta nuestros días con muchísima vitalidad (Martínez Rubio, 2015). Tales estudios plantaron las bases de una nueva concepción de la literatura desde la academia, y se manifestaron bien en la implantación de los Cultural Studies en ámbitos universitarios, bien en la incorporación de esas manifestaciones literarias ambiguas en programas, suplementos literarios y posibilidades de lectura del público más reticente.

Así pues, de manera progresiva se reconoce la función comunicacional de la historieta y resurge renovada, con importantes cambios inherentes tanto al diseño gráfico en sí como, especialmente, a las temáticas, los géneros y la narrativa. A modo de ejemplo, valga apuntar el dinámico debate generado por el concepto "novela gráfica" (García, 2010). De este modo, esta transformación ha originado un conjunto de obras que, a la función primera de entretener, unen la de reflexionar sobre aspectos y problemas concretos de la sociedad, así como una propuesta de lectura crítica dirigida a lectores maduros. Siguiendo la idea de Santiago García (2010), en la historieta como género ha operado una toma de conciencia desde cuyos planteamientos han surgido relevantes obras, entre las que destacan Maus (Art Spiegelman), El Eternauta (Oesterheld), Adolf (Tezuka), Paracuellos (Giménez), From Hell (Campbell / Moore), El grito del pueblo (Tardi), Trazo de tiza (Miguelanxo Prado), Valentina (Guido Crepax), V for Vendetta (Alan Moore), No pasarán (Vittorio Giardino), Persépolis (Marjanie Satrapi) o Palestine (Joe Sacco).

De esta manera, en el marco de los usos públicos del pasado, la historieta también ha venido a configurar un artefacto de memoria colectiva capaz de trasmitir las preocupaciones propias de artistas que impregnan su obra de una mirada responsable con el entorno. Así, al igual que han hecho la literatura, la pintura o el cine, de igual modo el cómic ha mostrado su vigor subversivo al plantear interrogantes, al cuestionar y desestabilizar las representaciones del pasado. $Y$ no solo: desde ese compromiso social, el cómic ha permitido representaciones alternativas de temas como la enfermedad, la crisis social, la marginalidad, la crisis política, la identidad nacional, los movimientos sociales, la violencia de Estado o la desigualdad de género. Siguiendo esta senda, algunas manifestaciones similares, como el humor gráfico, la viñeta o recientemente los memes o montajes de internet, tienen el plus de alcanzar a un público más amplio, convirtiéndose en soporte idóneo para la reflexión sobre determinados hechos históricos, procesos traumáticos o temas 
sociales, cuando no de punta de lanza de discursos más elaborados o de posiciones políticas que los sostienen y que los generan.

Por todo esto, con el presente número monográfico pretendemos potenciar la consolidación del análisis de la historieta en el mundo académico. Un proceso que ya ha comenzado a llevarse adelante no solo por medio de estudios, como apuntábamos, sino también por las posibilidades de debate que se entablan en reuniones académicas y en grupos de investigación. Ejemplo de ello son los congresos Cómic y compromiso Social (Universitat de València), Guerra Civil Española y Cómic (Université Blaise Pascal), Viñetas Serias (Universidad de Buenos Aires), o iniciativas como la creación del Laboratorio para el estudio literario de cómic de la Università Ca' Foscari di Venezia, o la revista Tebeosbera, que agrupa a especialistas de diferentes disciplinas, o las Jornadas universitarias Unicómic de la Universitat d'Alacant, que van ya por su XVII edición. Todos ellos, desde disímiles modos y perspectivas, han trabajado para el arraigo de la investigación del cómic, y han acompañado también este proyecto monográfico. Vaya por delante nuestro agradecimiento.

Destacamos, con el mismo objetivo, el carácter internacional de las aportaciones recibidas, ya que esto deja en evidencia una preocupación activa de los investigadores de Argentina, España, Francia, Italia y México, por la historieta como medio de representación de las diferentes problemáticas que han inquietado a los creadores del siglo XX y XXI. En los estudios que proponemos se hace patente la capacidad del cómic para fraguar nuevos debates, para acompañar los cambios sociales, para dar voz y cuerpo a quienes han sido invisibilizados en guerras, luchas de género, crisis económicas, movimientos migratorios, etc. Todos los autores y autoras tienen como hilo conductor la noción de un arte de acción, por lo tanto, sus planteamientos están atravesados por obras que enarbolan la creación como estandarte de libertad y como mecanismo de denuncia ante la injusticia. Ejemplo de este arte de acción es la portada del monográfico, a cargo de la ilustradora Maria Herreros, ya que sus dibujos sintetizan el sentido de "Historieta y sociedad".

Hemos distribuido las aportaciones científicas priorizando la coherencia temática. En primer lugar se aborda la guerra civil española y el franquismo. Inaugura esta línea un exhaustivo estudio de la profesora Viviane Alary, de la Université Blaise Pascal, Clemont-Ferrand. En el mismo, desde una perspectiva diacrónica que va desde 1936 hasta la actualidad, se analiza la presencia de la Guerra Civil en la historieta. Alary se detiene en la variedad genérica y estética de los relatos gráficos, pero también en la función que cumplieron estas publicaciones en cada momento histórico. La autora propone un tratamiento de la historieta como "literatura testimonial 
en segundo plano" y postula que "la historieta debe formar parte del registro escrito de la historia de la Guerra Civil", "entrar en los archivos y en los distintos procesos de catalogación institucional". El segundo artículo, a cargo de Néstor Bórquez (Universidad Nacional de la Patagonia Austral) se centra en la producción gráfica de los últimos años en torno a la memoria histórica. Su trabajo plantea la categoría de "historieta de la memoria", a partir de ella establece patrones entre las obras de Carlos Giménez, Antonio Altarriba y Paco Roca. Resalta igualmente las características que estos cómics tienen en común con la literatura de la memoria, cruce que se ve enriquecido por la apertura de los estudios literarios y la reciente permeabilidad a una "hibridez genérica". Desde otra perspectiva, aunque continuando con el tópico de la Guerra Civil, Didier Corderot (Université Blaise Pascal-Celis) repasa la vanguardia al servicio de la propaganda rebelde a partir de la producción de Tono, seudónimo de Antonio de Lara. El artículo indaga en las influencias que permiten al dibujante un trazo distintivo y en su colaboración con las revistas Vértice y La Ametralladora. Si Didier aborda las tonerías en un marco convulso previo a la dictadura, Raquel Macciuci (Universidad Nacional de La Plata) avanza treinta años en la historia española y se centra en la novela gráfica Chumy Chúmez. Una biografía, producida en los años finales del régimen franquista. La autora analiza la obra recomponiendo tanto el contexto político como el sistema literario y artístico de los años 70, e infiere que la producción de Chumy Chúmez revela "un cambio de ciclo, histórico y estético".

La segunda parte temática está dedicada al cómic internacional como generador de revoluciones dentro del sistema, ya sea en cuanto al mercado editorial con la obra argentina Mort Cinder, en la lucha de géneros con la francesa Ah! Nana, o en la construcción de una identidad nacional mexicana con El gallito inglés. Comienza este bloque la especialista Laura Vazquez (Universidad de Buenos Aires) con la recuperación de Mort Cinder, producción que lleva el inconfundible sello de Oesterheld y Breccia. Vazquez rastrea la tensión entre arte y mercado en el contexto rioplatense de los años sesenta, y expone cómo el carácter experimental de este cómic produce una ruptura en la técnica y un corte con la lógica industrial, sintetizado en "la fatiga de los materiales y de las formas". Continúa este segundo itinerario Adela Cortijo Talavera con un artículo centrado en el trabajo de las autoras de la revista francesa Ah! Nana (1976-1978). La investigadora de la Universitat de València reivindica la mirada subversiva de la publicación y la ruptura de estereotipos, ya sea en la representación del cuerpo femenino o en el impacto que el lector podía tener ante portadas con "temas controvertidos" como la homosexualidad, la pedofilia, el neonazismo, el sadomasoquismo, el incesto o la violencia hacia la mujer. Finaliza este 
segundo bloque Gonzalo Lizardo Méndez (Universidad de Zacatecas), rescatando la importancia de los autores Avrán, Luis Fernando y Clément en El gallito inglés, revista independiente que en los años 90 se enfrenta a la hegemonía del mercado editorial mexicano. La propuesta gráfica de quienes estaban nucleados en la publicación es analizada como una redefinición de la identidad mexicana que absorbe tanto la recuperación de una estética tradicional como el influjo del rock, la pintura y el cine.

Cierra este monográfico un tercer bloque dedicado a la crisis europea actual vista desde las viñetas. La primera contribución es la de Lisa Maya Quaianni Manuzzato, que formula una comparación entre la producción española y la italiana, entre 2011 y 2015. A partir de los cómics, tanto individuales como colectivos, que muestran una preocupación por el paro, los desahucios, los bancos, la inmigración y la falta de oportunidades, analiza la influencia del 15-M en los dibujantes, la recuperación de los métodos vanguardistas y la vuelta a un arte politizado. El estudio aporta, además, entrevistas inéditas a los autores. Casi a modo de continuación con el trabajo de Maya Quaianni, el apartado BAZA DE TEXTOS concluye con el aporte de Thomas Faye (Université de Limoges). Su artículo recupera el reportaje gráfico como compromiso periodístico a partir de Los vagabundos de la chatarra, del escritor Jorge Carrión y el dibujante Sagar.

Como complemento de los estudios críticos, el lector podrá encontrar en el apartado SOBRETEXTOS, además de las habituales reseñas de poesía y novela, recomendaciones de cómics, publicados en 2015 y 2016, que abordan temas sociales.

Finalmente, no queremos acabar esta presentación sin mencionar que el presente número monográfico está dedicado al profesor Joan Oleza, director de la publicación diablotexto (1994-2004) y director honorífico de Diablotexto digital. Porque como tutor nos ha mostrado los pasos para hacer una investigación, pero como maestro nos han enseñado a mirar, a cuestionar, a indagar y a rebelarnos, sobre todo, porque nos ha mostrado con su labor diaria, con su acción continua, el nexo entre vida, arte y compromiso social.

\section{Bibliografía}

Eco, Umberto (1964). Apocalittici e integrati: comunicazioni di massa e teorie della cultura di massa. Milano: Bompiani.

GARcía, Santiago (2010). La novela gráfica. Bilbao: Astiberri Ediciones.

MARTíNEZ RUBIO, José (2015). Las formas de la verdad. Investigación, docuficción y memoria en la novela hispánica. Barcelona: Anthropos.

WOLFE, Tom [1973] (1977). El nuevo periodismo. Barcelona: Anagrama. 